BULLETIN Bulletin hispanique

HISPANIQUE Université Michel de Montaigne Bordeaux

$119-2 \mid 2017$

La Égloga renacentista en el Reino de Nápoles

\title{
Eduardo José Jacinto García, Forma y función del diccionario. Hacia una teoría general del ejemplo lexicográfico
}

Servicio de Publicaciones de la Universidad, Jaén, 2015

José Carlos Huisa Téllez

\section{OpenEdition}

\section{Journals}

Edición electrónica

URL: http://journals.openedition.org/bulletinhispanique/5251

DOI: 10.4000/bulletinhispanique.5251

ISSN: 1775-3821

Editor

Presses universitaires de Bordeaux

Edición impresa

Fecha de publicación: 1 diciembre 2017

Paginación: 796-799

ISBN: 979-10-300-0218-8

ISSN: 0007-4640

\section{Referencia electrónica}

José Carlos Huisa Téllez, «Eduardo José Jacinto García, Forma y función del diccionario. Hacia una teoría general del ejemplo lexicográfico», Bulletin hispanique [En línea], 119-2 | 2017, Publicado el 01 diciembre 2017, consultado el 14 enero 2021. URL: http://journals.openedition.org/bulletinhispanique/ 5251 ; DOI: https://doi.org/10.4000/bulletinhispanique.5251

Este documento fue generado automáticamente el 14 enero 2021

Tous droits réservés 


\section{Eduardo José Jacinto García, Forma y función del diccionario. Hacia una teoría general del ejemplo lexicográfico}

Servicio de Publicaciones de la Universidad, Jaén, 2015

José Carlos Huisa Téllez

\section{REFERENCIA}

Eduardo José Jacinto García, Forma y función del diccionario. Hacia una teoría general del ejemplo lexicográfico. - Jaén, Servicio de Publicaciones de la Universidad, 2015, 146 p. Colección Seminario de Lexicografía Hispánica. Materia: Filología; Lingüística. ISBN 978-84-8439-900-1

1 Todavía resulta una idea de sentido común muy extendida entre los usuarios de obras lexicográficas que la práctica correspondiente, esto es, la mera elaboración de diccionarios, se limita al registro de unidades léxicas y a la redacción de sus respectivas definiciones. En el campo científico, sin embargo, la llamada metalexicografía - la reflexión teórica sobre tal práctica lexicográfica basada en la revisión de la producción occidental ya existente - ha alcanzado niveles muy altos de desarrollo y de abstracción. Mientras que en la tradición de habla española se presta mayor atención a la historia del registro de unidades léxicas, tomando en cuenta la información sociohistóricocontextual, en países centroeuropeos, sobre todo en Alemania a partir de la obra de Wiegand, Hausmann y Werner, se ha tendido, sin perder de vista lo anterior, a la revisión y clasificación de las formas textuales a través de las cuales un diccionario ofrece información, en especial sobre las unidades que recoge. Esta perspectiva científica, si bien no explícitamente, aporta además pautas importantes para la adecuada elaboración de nuevos diccionarios.

2 Formado en esta tradición alemana, Eduardo Jacinto se inicia con la monografía que ahora reseñamos en la titánica tarea de trasladar este punto de vista alemán a la 
tradición metalexicográfica de habla española, tal como ya han hecho investigadores como Bustos Plaza, Fuentes Morán o Model. En este primer libro, el autor se centra en un elemento bastante bien determinado de la microestructura: el ejemplo lexicográfico. Es necesario recordar desde una perspectiva historiográfica que en el caso de las lenguas románicas, como el español y el francés, el estudio del ejemplo en los diccionarios pasa con frecuencia por un tamiz fuertemente ideológico, consecuente con contextos de estandarización lingüística y que responde a una tradición latina bien establecida: basta pensar aquí en la noción de autoridad. En el caso de la metalexicografía alemana, por otra parte, libre de esta perspectiva historiográfica, se plantean cuestiones que apuntan, más bien, a la forma y función de un ejemplo dentro de las estrucutras del diccionario. En este marco, y tal como subtitula su trabajo, Jacinto se propone el objetivo de presentar una teoría general del ejemplo lexicográfico.

Tras el Prólogo escrito por Ignacio Ahumada (CSIC), el estudio se abre con una Introducción, en la que el autor presenta los fundamentos teóricos de su trabajo. Se enumeran, en primer lugar, los diferentes modelos metalexicográficos que se han ido erigiendo desde mediados del siglo pasado para enfrentarse al análisis de los diccionarios desde una perspectiva científica. Se distinguen, así, un primer paradigma estructuralista, en el que la práctica lexicográfica se veía como parte de la lexicología aplicada; un paradigma semiótico, inaugurado por el clásico Étude linguistique et sémiotique des dictionnaires français (1971) de Rey-Debove, y un paradigma pragmático, denominado por el autor como modelo lingüístico-metalexicográfico, uno de cuyos principales representantes, el mexicano Luis Fernando Lara, sustenta la idea de que los diccionarios constituyen objetos verbales. Finalmente, se presenta el paradigma germano de la mano de las reflexiones de Wiegand, que apuntan a la elaboración de una teoría general del diccionario y de las que Jacinto presenta aquí un buen resumen, si bien apretadísimo, dejando en claro la forma en que se concibe la investigación del diccionario al enumerar y explicar los cuatro ámbitos de la investigación y sus correspondientes subteorías: del uso, de la crítica, de la historia y del procesos lexicográfico del diccionario. Nuestro autor se detiene en la teoría parcial sobre los componentes lexicográficos para señalar una de las ideas fundamentales de todo este constructo teórico: la de que «los diccionarios se definen como conglomerados textuales, es decir, como estructuras compuestas por textos de diferentes tipos, organizados y conectados entre sí según convenciones fijadas por la costumbre y por razones de índole práctica» (10).

El cuerpo central del libro, dedicado de lleno al fenómeno del ejemplo lexicográfico, está compuesto por dos grandes partes: aquella en la que se desarrollan cuestiones teóricas y la que apunta decididamente a la elaboración de una tipología del ejemplo lexicográfico. Esta segunda parte constituye, como resulta evidente, la más importante de la monografía; sin embargo, la primera tiene también relevancia, lo que se muestra en el planteamiento y el desarrollo, si bien un tanto desarticulado, de temas escogidos en torno al objeto de estudio. El esclarecimiento de tales temas resulta para el autor un paso necesario para alcanzar el objetivo principal del libro. En primer lugar, se postula -siguiendo en todo momento la estela del pensamiento de Wiegand- la necesidad de un acercamiento teórico serio y sistemático al ejemplo lexicográfico en el ámbito español, que lleve a su vez a la elaboración de una respectiva tipología, una «que no solo tenga en cuenta su origen (inventado o real), sino también su forma, su contenido y su función» ([13]). A propósito de este desideratum, el autor se permite reclamar una terminología precisa no solo para el tema en cuestión -discutiendo en qué medida la 
falta de ella en la tradición en español obstaculiza la descripción del fenómeno- sino también para la metalexicografía en general (de hecho, como veremos más adelante, se presenta al final de la obra un importante glosario). A continuación, y en la misma línea discursiva, se plantea la cuestión central de qué es realmente un ejemplo lexicográfico, para cuya respuesta discute en sendas secciones los problemas a la que la tradición científica se ha enfrentado en este campo: «¿Sintagma o enunciado?» (1.2.), en la que revisa esta vieja discusión, «¿Infralema o ejemplo traducido?» (1.3.), para el caso de los diccionarios bilingües y «Ejemplos y otras indicaciones», en la que se muestra que la función que cumple un ejemplo podría ser cumplida por otra indicación, por lo que definirlo desde este punto de vista, esto es, a partir de su finalidad, resultaría problemático. Tras tales reflexiones, Jacinto responde de la siguiente manera a la pregunta de partida dirigida a la definición del ejemplo en esta primera parte:

En conclusión, definir qué es un ejemplo lexicográfico depende a menudo de lo que el autor del diccionario ha entendido por tal. El ejemplo lexicográfico es ante todo una categoría de carácter formal. Es la forma la que determina que un componente sea concebido o interpretado como un ejemplo y no tanto su función (34).

5 En estas líneas, como vemos, se plantea tajantemente el punto de vista desde el cual el autor emprenderá en la segunda parte el análisis de su objeto de estudio. Una de las ideas fuertes que aparecen repetidas veces a lo largo de toda la monografía, si bien en el fragmento citado no se menciona directamente, es la de que una obra lexicográfica se elabora a partir de un objetivo determinado por su autor, al cual se adecuará la función del ejemplo. En este orden de ideas, es importante reparar en que -de acuerdo con la tradición metalexicográfica en la que se inscribe el estudio- la forma del ejemplo lexicográfico, esto es, la manera en que se incrusta en la microestructura, constituye un punto de análisis fundamental. Después de tocar otros tres temas relevantes -las fuentes de los ejemplos (3.), los principios de garantía (4.) y la cuestión de la metalengua (5.)-, Jacinto cierra esta primera gran parte de su libro volviendo en 6 . («Forma y función en la microestructura del diccionario») explícitamente a las minuciosas reflexiones teóricas de Wiegand sobre la estructura interna del artículo lexicográfico. Como en la Introducción, aquí nos encontramos frente a una muy buena presentación en español de las ideas del metalexicógrafo alemán.

6 La segunda parte del libro constituye el análisis en sí mismo del ejemplo lexicográfico, dividido en tres secciones dedicadas a tres niveles diferentes de análisis: en cuanto a la forma (1.), al contenido (2.) y a la función del ejemplo (3.). En este análisis, basado en un importante corpus de diccionarios en español clasificados según géneros lexicográficos, el autor desarrolla en primer lugar el tema central de su propuesta, el de la forma del ejemplo como criterio central para su tipologización, presentando dos dicotomías: condensado/libre sin indicación de fuente/con indicación de fuente. Se dedica, en seguida, a los otros dos criterios -el del contenido y el de la función-, tratados con mayor atención en la tradición metalexicográfica española, lo que, por cierto, puede ser una razón por la cual la extensión de esta parte sea significativamente mayor. El análisis se cierra con una sección titulada «Tipología del ejemplo lexicográfico» (4.), en la que se presenta finalmente una tabla que condensa todo lo dicho anteriormente.

7 En el apartado de Conclusiones, Jacinto presenta un buen resumen de las ideas que ha ido formulando a lo largo de su trabajo, en especial, aquella que apunta a que el ejemplo, en forma de unidad monoverbal o de una pluriverbal lexicalizada o no, debe definirse a partir de un criterio estrictamente formal y no de la finalidad para la que se presenta, porque esta depende de la naturaleza de la obra lexicográfica y del autor, en 
primer lugar, y porque además, el ejemplo puede cumplir más de una función en una misma obra e incluso en un mismo momento. Esta característica propia del ejemplo lo convierte en un elemento distinguido de la microestructura.

8 El libro se cierra con un glosario de términos metalexicográficos, provenientes especialmente de la tradición alemana, que no se restringe al tema tratado del ejemplo. Además de la evidente importancia que tal glosario tiene para los estudios metalexicográficos en nuestra lengua, se muestra con su elaboración nuevamente la intención de Jacinto de trasladar las reflexiones de Wiegand al ámbito español, lo que puede considerarse desde una perspectiva más general el aporte de fondo más importante del autor.

\section{AUTORES}

JOSÉ CARLOS HUISA TÉLLEZ

Université Johannes Gutenberg - Allemagne 